\title{
Bør traumatiske hudsår lukkes innen åtte timer?
}

\begin{abstract}
BAKGRUNN I allmennmedisinen har det vært vanlig praksis å avstå fra primær lukking av traumatiske hudsår hvis det har gått mer enn 6-8 timer etter skaden. Man har ansett at primær sårlukking senere enn dette øker infeksjonsrisikoen betydelig. Denne tidsgrensen har sin opprinnelse i gamle dyrestudier. Først i de senere tiår er det kommet kliniske studier med uselekterte pasienter i allmennpraksis. Hensikten med denne artikkelen var å undersøke det vitenskapelige grunnlaget for denne tidsgrensen.
\end{abstract}

KUNNSKAPSGRUNNLAG Det ble søkt i PubMed etter kliniske studier med uselekterte pasienter med akutte traumatiske hudsår behandlet med sårlukking i allmennpraksis, inkludert legevakt. Sammenhengen mellom tid fra skade til primær sårlukking og infeksjonsrisiko ble undersøkt.

RESULTATER Fem kliniske studier ble funnet. I disse fant man ikke at sår må lukkes innen 6-8 timer for å unngå økt infeksjonsrisiko. Samtlige var prospektive observasjonsstudier fra legevakt. Studiene var heterogene, og de hadde alle lav vitenskapelig kvalitet.

FORTOLKNING I nyere klinisk forskning kan man ikke påvise en absolutt tidsgrense på 6-8 timer hvor traumatiske sår kan lukkes uten økt infeksjonsrisiko. Mange sårskader kan sannsynligvis lukkes senere enn dette uten at faren for infeksjon blir større. Godt vitenskapelig funderte retningslinjer vil ikke foreligge før man har resultater fra robuste randomiserte, kontrollerte studier.

Lukking av traumatiske hudsår er svært vanlig i allmennpraksis. Beregnet ut fra kombinasjonen av ICPC-2-diagnosekode (kode S 18: åpent sår/kutt) og takstbruk (takst 149a: lokalbedøvelse, takst 100: prosedyretakst, inkludert sår behandlet med sutur) ble det $\mathrm{i}$ 2012 suturert over 33000 sår i primærhelsetjenesten i Norge (data fra Helfo analysert ved Nasjonalt kompetansesenter for legevaktmedisin, personlig meddelelse).

Det har i alle år vært godt innarbeidet i norsk allmennmedisin at traumatiske hudsår bør lukkes innen 6-8 timer etter skadetidspunktet for å unngå betydelig økt infeksjonsrisiko. Tidsintervallet kan økes ved sårskader i hode og ansikt, kanskje til 24 timer. Mye brukte norske oppslagsverk i allmennmedisin, som Norsk Elektronisk Legehåndbok, Legevakthåndboken, den store norske læreboken i allmennmedisin samt Kirurgi $i$ allmennpraksis, opererer med disse tidsfristene (1-4).

Fristen på 6-8 timer for sårlukking uten forhøyet infeksjonsrisiko bygger på teorien om at bakterier i en sårskade vil holde seg lokalt $\mathrm{i}$ såret $\mathrm{i}$ en begrenset tidsperiode før de blir invasive. Ved god lokal rengjøring og revisjon av såret før dette skjer vil det derfor i mindre grad bli kolonisert med bakterier og kan lukkes primært uten at infeksjonsfaren er økt. Denne tidsperioden benevnes i engelskspråklig litteratur som «the golden period of wound repair» (5).

Forestillingen om eksistensen av en begrenset periode der sårlukking kan skje uten øt infeksjonsfare, etter rensing og eventuell revisjon av såret, bygger på dyrestudier fra slutten av 1800-tallet, utført av den tyske kirurgen Paul Leopold Friedrich (1864-1916). Teorien ble fremlagt for første gang på en kirurgikongress i Berlin i april 1898 (6).

Inntil nylig har disse tidsfristene for sårlukking levd videre i lærebøker og artikler uten å ha blitt etterprøvd i studier med uselekterte pasienter i vanlig klinisk praksis før i de senere tiår. Hensikten med denne gjennomgangen er å undersøke det vitenskapelige grunnlaget for denne tidsgrensen.

\section{Kunnskapsgrunnlag}

Det ble søkt i PubMed etter engelskspråklige artikler med studier hvor et av forskningsspørsmålene var sammenhengen mellom tid fra traumatisk sårskade til sårlukking og infeksjonsrisikoen hos uselekterte pasienter behandlet $\mathrm{i}$ allmennpraksis, inkludert legevakt. At det var uselekterte pasienter, innebar at studiene ikke skulle være begrenset til bare enkelte anatomiske lokalisasjoner eller spesifikke skademekanismer, heller ikke avgrenset til spesifikke pasientgrupper. Studier hvor barn var ekskludert, ble inkludert i kunnskapsgrunnlaget såfremt pasientene for øvrig var uselekterte.

To søk ble gjort i PubMed (1.8. 2013). Søkestrengene «traumatic wound and closure and infection» og «golden period wound repair» ble brukt. Det var ingen tidsbegrensninger på søket.

Ved det første søket («traumatic wound

\section{Knut Steen}

knut.steen@bergen.kommune.no

Bergen legevakt

Se også kunnskapsprøve på www.tidsskriftet.no/quiz

> Se lederartikkel på side 1633

\section{HOVEDBUDSKAP}

Primær lukking av traumatiske hudsår senere enn åtte timer etter skade har vært ansett for å øke infeksjonsrisikoen

Resultater fra kliniske studier gir ikke støtte til denne tidsfristen

Mange sårskader kan sannsynligvis lukkes senere enn åtte timer etter skade uten økt infeksjonsrisiko 
Tabell 1 Oversikt over kliniske studier om tid fra skade til primær sårlukking versus infeksjonsrisiko

\begin{tabular}{|c|c|c|c|c|c|}
\hline Førsteforfatter & Berk WA (10) & Hollander JE (7) & van den Baar MT (8) & Quinn JV (9) & Waseem M (11) \\
\hline Land & Jamaica & USA & Nederland & USA & USA \\
\hline$\AA ̊ \cap$ & 1986 & $1992-96$ & $2005-07$ & $2008-09$ & $2009-10$ \\
\hline Antall pasienter & 204 & 5521 & 408 & 2663 & 297 \\
\hline Frafall (\%) & 45 & Ikke oppgitt & 4 & 33 & 11 \\
\hline Infeksjonsrate [\%] & $16,2^{1}$ & 3,5 & $9(2,7)^{2}$ & 2,6 & 3,4 \\
\hline \multirow[t]{4}{*}{ Hovedfunn } & $\begin{array}{l}\text { Ikke-signifikant forskjell } \\
\text { i tilhelingsrater på sår } \\
\text { lukket før og etter } \\
12 \text { timer etter skade. } \\
\text { P > 0,05 } \\
\text { Signifikant forskjell i til- }\end{array}$ & \multirow[t]{2}{*}{$\begin{array}{l}\text { Ikke-signifikant for- } \\
\text { skjell i tid fra skade } \\
\text { til sårlukking for infi- } \\
\text { serte og ikke-infiserte } \\
\text { sår (gjennomsnitt } \\
\text { i timer med standard- } \\
\text { avvik): }\end{array}$} & $\begin{array}{l}\text { Ikke-signifikant for- } \\
\text { skjell i infeksjonsrate } \\
\text { for sår lukket før og } \\
\text { etter } 6 \text { timer etter } \\
\text { skade: } \\
\text { OR 1,096 } 195 \% \mathrm{KI}\end{array}$ & $\begin{array}{l}\text { Ikke-signifikant forskjell } \\
\text { i tid fra skade til sårluk- } \\
\text { king for infiserte og ikke- } \\
\text { infiserte sår (gjennom- } \\
\text { snitt i timer med stan- } \\
\text { dardavvik): }\end{array}$ & $\begin{array}{l}\text { Tid fra skade til sår- } \\
\text { lukking signifikant } \\
\text { lengre i infeksjons- } \\
\text { gruppen enn i gruppen } \\
\text { uten infeksjon (median } \\
\text { og gjennomsnitt } \\
\text { i minutter): }\end{array}$ \\
\hline & \multirow{3}{*}{$\begin{array}{l}\text { Signifikant forskjell i til- } \\
\text { helingsrate for sår luk- } \\
\text { ket før og etter } 19 \text { timer } \\
\text { etter skade: } 92,1 \% \text { ver- } \\
\text { sus } 77,4 \%, p<0,01\end{array}$} & & \multirow{3}{*}{$\begin{array}{l}\text { OR } 1,096(95 \% \mathrm{KI} \\
0,305-3,935) . P=0,889\end{array}$} & $\begin{array}{l}2,4(1,9) \text { versus } 3,0(4,9) \\
P=0,39\end{array}$ & \multirow{3}{*}{$\begin{array}{l}867,0(944,5) \text { versus } \\
330,0(578.9) . P=0,03\end{array}$} \\
\hline & & \multirow{2}{*}{$\begin{array}{l}3,0(5,6) \text { versus } 2,1 \\
(3,5) . P=0,08\end{array}$} & & $\begin{array}{l}\text { lkke-signifikant forskjell } \\
\text { i infeksjonsrate for sår } \\
\text { lukket før og etter } \\
12 \text { timer fra skade: }\end{array}$ & \\
\hline & & & & $\begin{array}{l}2,9 \%(95 \% \mathrm{KI} 2,3-3,8 \%) \\
\text { versus } 1,5 \%(95 \% \mathrm{KI} \\
0,03-6,4 \%)\end{array}$ & \\
\hline
\end{tabular}

${ }^{1}$ Manglende tilheling, definert som infeksjon og/eller manglende epitelialisering av såret

${ }^{2}$ Ved mer restriktiv definisjon av infeksjon

and closure and infection») var det 162 treff. Av disse ble 154 artikler ekskludert på grunnlag av overskriften, idet de ut fra den alene åpenbart ikke fylte de forhåndsdefinerte inklusjonskriteriene. Sammendragene ble lest for de resterende åtte, og tre av disse fylte inklusjonskriteriene (7-9).

Ved det andre søket («golden period wound repair») var det 16 treff. 13 artikler ble ekskludert på grunnlag av overskriften alene, tre sammendrag ble lest og to artikler inkludert $(10,11)$.

\section{Resultater}

Tabell 1 (7-11) gir en kort oppsummering av de fem studiene med hovedfunn. I tre av de fem var det ingen sammenheng mellom tid fra skade til sårlukking og infeksjonsrisiko (7-9). I en studie fant man ingen sammenheng når det gjaldt sår lukket før og sår lukket etter 12 timer etter skade, men for sår lukket før og etter 19 timer var det sammenheng (10). Bare i én studie var det en sikker sammenheng mellom tid fra skade til sårlukking og infeksjonsrisiko (11). Imidlertid var gjennomsnittlig tid fra skade til sårlukking ganske lang i denne studien, både for infiserte og ikke-infiserte sår, henholdsvis 15,7 timer og 9,7 timer (11).

Samtlige var prospektive observasjonsstudier med uselekterte pasienter som hadde henvendt seg til legevakt (emergency department, ED, eller emergency room, ER) for behandling av traumatiske sårskader. I tre av studiene var pasientene voksne $(8,10,11)$, mens spesifikke aldersgrenser ikke fremgikk i de to andre $(7,9)$. I alle de fem studiene ble det brukt ulike variabler som kunne tenkes å påvirke infeksjonsrisikoen etter sårlukking. Kun to studier hadde tid fra skade til sårlukking versus infeksjonsrisiko som sitt hovedforskningsspørsmål $(8,10)$. I to studier ble mange faktorer undersøkt, men tidsfaktoren var spesielt vektlagt $(9,11)$. I en vurderte man mange ulike faktorer som kunne tenkes å påvirke infeksjonsrisikoen, og tidsfaktoren var en av disse (7).

Den totale infeksjonsraten varierte fra $2,6 \%$ (9) til 9\% (8). Infeksjonsrater på $3,4 \%$ (11) og 3,5\% (7) ble også rapportert. Definisjonen på sårinfeksjon var forskjellig i de ulike studiene. I studien med høyest infeksjonsrate $(9 \%)$ ble enhver rødhet definert som infeksjon (8), mens man i studien med lavest infeksjonsrate $(2,6 \%)$ brukte antibiotikabehandling som kriterium på sårinfeksjon (9). I studien med høyest infeksjonsrate brukte man imidlertid også en mer restriktiv definisjon på infeksjon, og raten sank da til 2,7\% (8).

Videre ble infeksjon vurdert enten ved suturfjerningstidspunktet $(8,10,11)$ eller telefonisk undersøkt 30 dager etter sårlukking (9), eventuelt var det en kombinasjon av klinisk vurdering og telefonoppfølging (7). Ulike definisjoner på infeksjon samt ulike måter og tidspunkter å vurdere dette på gjør sammenlikning av infeksjonsratene i de ulike studiene problematisk. Men i majoriteten av studiene fremgikk det at tid fra skade til sårlukking ikke var en signifikant faktor for utvikling av sårinfeksjon.

Studiene var heterogene. I fire inndelte man materialet $\mathrm{i}$ infiserte og ikke- infiserte sår etter sårlukking og analyserte det ut fra dette (7, 9-11). I en av disse studiene analyserte man i tillegg materialet ut fra om såret var lukket før og etter 12 timer etter skade (9). I en studie skilte man mellom sår suturert før og sår suturert etter seks timer etter skaden (8).

Sårskadene ble lukket med sutur i fire av studiene $(7,8,10,11)$, mens det $i$ en studie ble brukt både sutur $(64 \%)$, lim, teip eller stifter, eventuelt en kombinasjon av disse (9). I to av studiene fremgikk det eksplisitt at alle hudsår ble lukket uavhengig av når skaden hadde inntruffet såfremt det klinisk ikke syntes å være sårinfeksjon $(8,10)$. I en annen studie syntes også dette å være tilfellet, uten at det var nevnt eksplisitt (11), og i en av studiene fremgikk ikke dette (7).

I studien til Quinn og medarbeidere så det ut til å være en del «gamle» sår (over 12 timer siden skade) som ble behandlet åpent uten sårlukking (13 av 85 slike sår), med den resultatvridning med henblikk på infeksjon dette kunne tenkes å gi (9). I tre av studiene var alle bittskader ekskludert (9-11), i en av studiene var de inkludert (7) og i en annen er dette ikke nevnt (8). 
Tabell 2 (7-10) viser faktorer som påvirker infeksjonsrisikoen ved lukking av traumatiske hudsår. I flere av studiene var det økt infeksjonsrisiko ved pasientfaktorer som økende alder $(7,8)$ og diabetes mellitus $(7$, 9) eller sårfaktorer som stort sår (lengde over $5 \mathrm{~cm}$ ) (9), gapende sår (7), forurenset sår (9), fremmedlegeme i sår (7) og sår på ekstremiteter, spesielt underekstremiteter $(8$, 10). Sår lokalisert til hode/hals hadde redusert infeksjonsrisiko $(7,9,10)$. Yngre pasienter hadde lavere infeksjonsrisiko enn eldre $(7,8)$.

I en forholdsvis liten amerikansk studie fant man at hvite pasienter hadde høyere infeksjonsrate enn pasienter med annen etnisitet (11). Det ble ikke gjort noe forsøk på å kontrollere for underliggende faktorer (konfundering) i denne studien, og funnet er heller ikke rapportert i andre studier. Det er tvilsomt om det har generell relevans, og det er heller ikke tatt med i oppsummeringen i tabell 2.

\section{Diskusjon}

Med bakgrunn i den store hyppighet av traumatiske sårskader er det forbausende få undersøkelser der man har sett på infeksjonsrisikoen ut fra tid fra skade til sårlukking. Det ble bare funnet fem nyere engelskspråklige studier med uselekterte pasienter fra allmennpraksis, alle fem fra legevakter. Tre av disse er fra USA $(7,9,11)$, en er fra Nederland (8) og en fra Jamaica (10). Den sistnevnte er noe eldre enn de andre, men det er den første kliniske studien der problemstillingen er nærmere undersøkt $\mathrm{i}$ en uselektert pasientpopulasjon. Den er derfor mye sitert.

Legevaktene i disse studiene var alle tilknyttet sykehus og hadde fast ansatte leger og sykepleiere. Både skadepanorama, behandlingstradisjoner og kompetanse er sannsynligvis forskjellig fra norsk allmennmedisin og legevakt. Overføringsverdien til norske forhold er derfor usikker.

I tre av studiene er det brukt multivariat analyse for å finne den relative betydningen av de ulike variablene $(7,8,9)$. Denne analysemetoden er ikke anvendt $\mathrm{i}$ de to andre $(10,11)$.

Studiepopulasjonen er liten i flere av studiene (totalt noen få hundre), og gruppene av pasienter med sårinfeksjon eller pasienter med «gamle» primærsuturerte sår blir dermed også små - med noen få titall pasienter eller enda færre $(8,10,11)$. Dette gjelder også studien der man fant sammenheng mellom tid fra skade til sårlukking og infeksjonsrisiko (11). I de to største undersøkelsene, med studiepopulasjoner på flere tusen, var det imidlertid ingen sammenheng mellom tid fra sårskade til lukking av såret og infeksjonsrate $(7,9)$.

I studien fra Jamaica var det ingen sammenheng mellom tilhelingsrate og infeksjon når det gjaldt sår lukket før og etter 12 timer fra skadetidspunktet, men det var sammenheng for sår lukket før og etter 19 timer (10). Imidlertid er den vitenskapelige kvaliteten spesielt lav i denne studien, og betydningen av dette funnet blir tilsvarende usikkert.

Blinding ved vurdering av sårinfeksjon er det enten ikke gjort spesielt rede for $(8,10$, 11) eller det er ikke gjennomført konsekvent (7). Alle undersøkelsene er prospektive observasjonsstudier, ingen av dem er randomiserte og kontrollerte. Frafallet er stort i flere av studiene, med den risiko for resultatvridning (bias) som dette medfører. Størst er det i studien fra Jamaica (45\%) (10), men det er også betydelig i andre studier $(33 \%$ og $11 \%)(9,11)$. Samlet sett må kvaliteten på studiene vurderes som lav, noe som medfører at man må være varsom med å trekke bastante konklusjoner.

En oversiktsartikkel i Injury med gjennomgang av studier om infeksjonsrisiko i forhold til tid fra traumatisk hudskade til sårlukking ble publisert i 2012 (12). Fire studier er omtalt der, hvorav to allerede er nevnt i denne artikkelen $(8,10)$. I tillegg omhandler artikkelen to studier der man har undersøkt infeksjonsrisikoen i selekterte pasientgrupper, den ene hos barn behandlet ved et barnesykehus i USA ( $n=2812)$, den andre ved sårskader i hånd og underarm med to ulike profylaktiske antibiotikaregimer $(n=217)$. Bare i den sistnevnte var det sammenheng mellom infeksjonsrate og tid fra skade til sårlukking.

Forfatterne av oversiktsartikkelen vurderer kvaliteten på alle studiene som lav, og det er stor spennvidde i infeksjonsratene (1,4-32\%). De konkluderer med at eksisterende studier ikke gir støtte til forestillingen om en begrenset tidsperiode hvor sår kan lukkes uten økt infeksjonsrisiko (the golden period).

I Cochrane-biblioteket finnes det også en gjennomgang av spørsmålet, siste versjon ble publisert i 2013 (13). Forfatterne konkluderer med at det ikke finnes studier av tilfredsstillende vitenskapelig kvalitet til å vurdere problemstillingen. Derfor anbefales det at klinikere inntil videre følger den til enhver tid gjeldende erfaringsbaserte kliniske praksis. Men det er et stort behov for robuste, randomiserte studier der man sammenlikner tidlig primærsutur innen $6-8$ timer med forsinket primærsutur innen 24 timer etter skade.

Årsaken til infeksjon etter sårlukking er multifaktoriell. Hvilken rolle tiden fra skade til lukking spiller i denne sammenhengen, er ikke sikkert klarlagt. I studiene som er referert over, finner man faktorer som både øker og reduserer infeksjonsfaren ved primær lukking av sår, både pasientfaktorer og sårfaktorer (tab 2). I nyere oversiktsartikler opererer man derfor med differensierte tidsfrister for lukking av traumatiske sårskader $(14,15)$.
Tabell 2 Faktorer som gir økt eller redusert infeksjonsrisiko ved lukking av traumatiske hudsår

\section{$\emptyset$ kt infeksjonsrisiko}

Sårfaktorer

Store sår (9)

Gapende sår (7)

Forurensede sår (9)

Fremmedlegeme i sår (7)

Sår på ekstremiteter $(8,10)$

Pasientfaktorer

Eldre $(7,8)$

Diabetes mellitus $(7,9)$

\section{Redusert infeksjonsrisiko}

Sårfaktorer

Sår på hode/hals $(7,9,10)$

Pasientfaktorer

Yngre $(7,8)$

I en oversiktsartikkel fra 1999 skriver Hollander \& Singer at det er en direkte relasjon mellom tid fra skade til sårlukking og infeksjonsrisiko, men at hver skade må vurderes individuelt. Spesifikke tidsgrenser nevnes ikke (14). En oversikt i American Family Physician fremhever at det er usikkert hvor lenge etter en skade et sår kan lukkes uten at det er økt infeksjonsrisiko, men at mange sår kan lukkes $i$ alle fall inntil 12 timer etter skaden og mange senere enn dette også, men etter individuell vurdering (15).

En kort gjennomgang av behandling av traumatiske hudsår er nylig publisert i $B M J$ (16). En tidsfrist på 24 timer for primær lukking av godt rengjorte, mindre sårskader anbefales her. Generelt synes det å være en utvikling mot at lengre tidsintervaller mellom skade og sårlukking aksepteres, men med individuell vurdering av hver enkelt sårskade. Dette er også i samsvar med retningslinjene i UpTodate, hvor det det anbefales at ikke-infiserte sårskader hvor som helst på kroppen hos ellers friske pasienter kan lukkes innen 18 timer etter skade og ansiktssår innen 24 timer. I enkelte utvalgte tilfeller kan sår lukkes opptil 48-72 timer etter at skaden har skjedd (17).

\section{Konklusjon}

Ifølge nyere kliniske studier er det ikke slik at traumatiske hudsår må lukkes innen $6-8$ timer etter skadetidspunktet for å unngå økt 
infeksjonsrisiko. Mange sårskader kan sannsynligvis lukkes senere enn dette uten at infeksjonsfaren øker. Både sårfaktorer og pasientfaktorer må vektlegges her.

Den vitenskapelige dokumentasjonen på området er imidlertid svak. Sikre anbefalinger vil ikke foreligge før man har resultater fra robuste randomiserte, kontrollerte studier.

Jeg takker C. Brudvik, Klinisk institutt 1, Universitetet i Bergen, og T.H. Bergh, S. Benrnardshaw og F. van Betten ved Bergen legevakt for gjennomlesing av manuskript og kommentarer. Takk til H. Sandvik. og S. Hunskår, Nasjonalt kompetansesenter for legevaktmedisin, for henholdsvis analyse av Helfo-data og gjennomlesing av manuskriptet med kommentarer.

\section{Knut Steen (f. 1955)}

er dr.med., spesialist i allmennmedisin og overlege. Han er også fastlege, tidligere militærlege og forsker ved Nasjonalt kompetansesenter for legevaktmedisin.

Forfatter har fylt ut ICMJE-skjemaet og oppgir følgende interessekonflikt: Han har mottatt honorar fra Gyldendal for revisjon av kapitlet om sårskader i Legevakthåndboken.

\section{Litteratur}

1. Norsk Elektronisk Legehåndbok (database). Skader i hud og bløtdeler. http://legehandboka.no/ (16.10.2013).

2. Steen K. Sårskader. Lukking. I: Johansen IH, Blinkenberg J, Arentz-Hansen C et al, red. Legevakthåndboken. Oslo: Gyldendal Akademisk, 2012. www.lvh.no/skader/saarskader/

grunnleggende_saarkirurgi/lukning (16.10.2013).

3. Brudvik C, Wold G, Hunskăr S. Skader og forgiftninger. I: Hunskår S, red. Allmennmedisin. Oslo: Gyldendal, 2013: 774-819.

4. Samdal F, Helseth A. Hud og bløtdelsskader: Kirurgi i allmennpraksis. Håndbok i chirurgia minor og suturteknikk for allmennpraktiserende leger og medisinske studenter. Bærums verk: Chirurgia Minor, 1995: 71-4

5. Trott AT. Wounds and lacerations. Emergency care and closure. 4. utg. Philadelphia, PA: Elsevier/ Saunders, 2012: 95-106.

6. 100 Jahre Friedrich 'sche Wundausschneidung Hartmann Wundforum 2/98. www. deboor.de/ 100_jahre_wundausschneidung.htm (16.10.2013).

7. Hollander JE, Singer AJ, Valentine SM et al. Risk factors for infection in patients with traumatic lacerations. Acad Emerg Med 2001: 8: 716-20.

8. van den Baar MT, van der Palen J, Vroon MI et al. Is time to closure a factor in the occurrence of infection in traumatic wounds? A prospective cohort study in a Dutch level 1 trauma centre. Emerg Med J 2010; 27: 540-3.

9. Quinn JV, Polevoi SK, Kohn MA. Traumatic lacerations: what are the risks for infection and has the 'golden period' of laceration care disappeared? Emerg Med J 2014: 31: 96-100.

10. Berk WA, Osbourne DD, Taylor DD. Evaluation of the 'golden period' for wound repair: 204 cases from a Third World emergency department. Ann Emerg Med 1988; 17: 496-500.
11. Waseem M, Lakdawala V, Patel R et al. Is there a relationship between wound infections and laceration closure times? Int J Emerg Med 2012: 5: 32

12. Zehtabchi S, Tan A, Yadav K et al. The impact of wound age on the infection rate of simple lacerations repaired in the emergency department. Injury 2012; 43: 1793-8.

13. Eliya-Masamba MC, Banda GW. Primary closure versus delayed closure for non bite traumatic wounds within 24 hours post injury. Cochrane Database Syst Rev 2013; 10: CD008574.

14. Hollander JE, Singer AJ. Laceration management. Ann Emerg Med 1999; 34: 356-67.

15. Forsch RT. Essentials of skin laceration repair. Am Fam Physician 2008; 78: 945-51.

16. Cals JW, de Bont EG. Minor incised traumatic laceration. BMJ 2012; 345: e6824.

17. deLemos D. Closure of skin wounds with sutures. UpToDate versjon 19.2. www.uptodate.com/ contents/closure-of-skin-wounds-with-sutures (1.8.2013.)

Mottatt 27.11. 2013, første revisjon innsendt 28.4. 2014, godkjent 19.6. 2014. Redaktør: Sigurd Høye. 